\title{
8
}
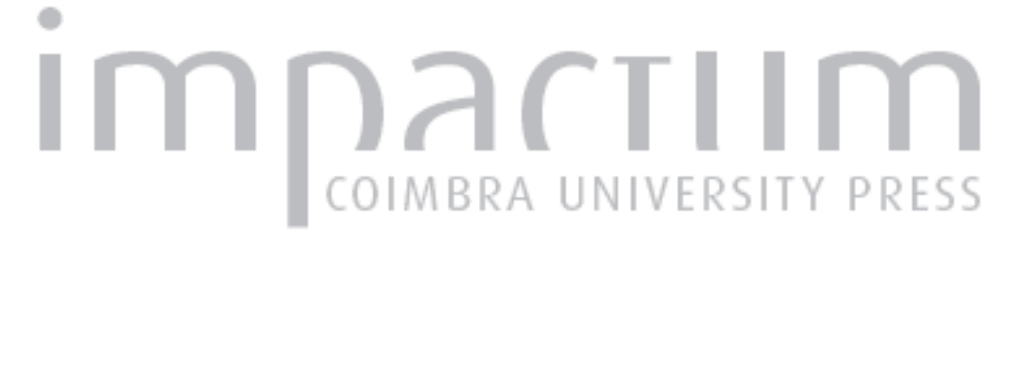

\section{As actividades humanas e os processos morfogenéticos: o exemplo da Serra do Marão}

Autor(es): $\quad$ Pedrosa, António de Sousa

Publicado por: Associação Portuguesa de Riscos, Prevenção e Segurança

URL persistente:

URl:http://hdl.handle.net/10316.2/40189

DOI:

DOI:https:/doi.org/10.14195/1647-7723_1_3

Accessed : $\quad$ 26-Apr-2023 07:25:08

A navegação consulta e descarregamento dos títulos inseridos nas Bibliotecas Digitais UC Digitalis, UC Pombalina e UC Impactum, pressupõem a aceitação plena e sem reservas dos Termos e Condições de Uso destas Bibliotecas Digitais, disponíveis em https://digitalis.uc.pt/pt-pt/termos.

Conforme exposto nos referidos Termos e Condições de Uso, o descarregamento de títulos de acesso restrito requer uma licença válida de autorização devendo o utilizador aceder ao(s) documento(s) a partir de um endereço de IP da instituição detentora da supramencionada licença.

Ao utilizador é apenas permitido o descarregamento para uso pessoal, pelo que o emprego do(s) título(s) descarregado(s) para outro fim, designadamente comercial, carece de autorização do respetivo autor ou editor da obra.

Na medida em que todas as obras da UC Digitalis se encontram protegidas pelo Código do Direito de Autor e Direitos Conexos e demais legislação aplicável, toda a cópia, parcial ou total, deste documento, nos casos em que é legalmente admitida, deverá conter ou fazer-se acompanhar por este aviso.

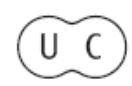




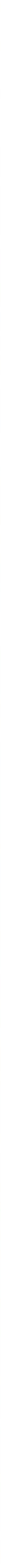




\title{
As actividades humanas e os processos morfogenéticos. O exemplo da Serra do Marão
}

\author{
António de Sousa Pedrosa *
}

\begin{abstract}
Resumo:
Neste trabalho procuramos contribuir para o estudo dos processos morfogenéticos responsáveis pela evolução geomorfologica actual da Serra do Marão e da influência que o homem exerce sobre a sua actuação. Apesar da importância que todos os factores de ordem fisica apresentam nas morfodinâmicas actuais, estas não podem ser compreendidas se não tivermos em atenção a actuaçăo do homem sobre o ambiente. O homem, com a capacidade de intervençåo que possui, pode modificar completamente a dinâmica morfogenética de qualquer área. Deste modo, torna-se cada vez mais premente estudar a maneira como se processa a sua aç̧̃̃o, naturalmente sem esquecer o passado, para se determinar, por um lado, os riscos a que o ambiente está sujeito e, por outro, os riscos que ele próprio corre. Os riscos não podem ser desconhecidos, têm de ser totalmente assumidos.

Palavras chave:

Serra do Marão, Norte de Portugal, Geomorfologia, processos morfogenéticos, acção humana, riscos.

Résumé:

Aveccetarticle nous prétendons contribuer àl'étude des processus morphogénétiques responsables parl'évolution géomorphologique actuelle de la Serra do Maråo (Nord du Portugal). La histoire ancienne du relief n'a pas été oubliée, mais le travail de l'homme sur les versants a été envisagé par son action morphogénétique et ses conséquences dans l'environnement en créant des risques. Ces risques ne pourront jamais être méconnus; au contraire, ils devront être assumés par l'homme.

Mots clés:

Serra do Marão, Nord du Portugal, Géomorphologie, processus morphogénétiques, action humaine, risques.

\section{Abstract:}

The aim of this article deals with the study of geomorphic processes on Serra do Marão (Northern Portugal) present day geomorphological evolution. The old history of landforms is not forgotten, but man's work on the slopes is shown with its consequences on the environment making some risks appear. This risks must be known and assumed by man.

Key Words:

Serra do Marão, North of Portugal, Geomorphology, geomorphic processes, man's action, risks.
\end{abstract}

\section{Introdução}

A Serra do Marão constitui um dos mais vigorosos conjuntos topográficos que se podem individualizar no grande alinhamento montanhoso que separa o Noroeste de Portugal dos planaltos transmontanos. Faz parte de um grupo de serras tradicionalmente vistas como um todo: o alinhamento montanhoso que separa o Minho de Trás-os-Montes, as duas regiões mais características do Norte de Portugal. Da fronteira com a Galiza para Sul, podemos aí individualizar as Serras da Peneda e do Gerês, o planalto do Barroso e as Serras do Alvão e do Marão, esta já adjacente ao grande vale do Douro. É ao longo deste conjunto montanhoso, ao qual se pode juntar a

\footnotetext{
*Professor Auxiliar.Instituto de Geografia.Facuildade deLetras. Universidade do Porto.
}

SerradoMontemuro, a Sul doDouro, que se encontram os pontos mais elevados do Norte de Portugal.

Este conjunto de serras e planaltos elevados constitui, pela sua altitude assim como pela sua massa, um obstáculo que determina uma transformação mais ou menos rápida do carácter temperado marítimo das paisagens pelo que normalmente é apelidado de barreira de condensação. Deste modo, a Serra do Marão insere-se num dos locais de maior precipitação do país e, ao mesmo tempo, numa das áreas de maiores contrastes no que se refere à distribuição das temperaturas, o que lhe confere uma particular individualidade entre as diversas serras portuguesas.

Com este estudo procuramos contribuir para conhecimentodos processos morfogenéticos responsáveis pela actual evolução morfológica da Serra do Marão e a influência que o homem exerce sobre a sua actuação. 


\section{As condições naturais}

A litologia é um factor importante para explicar algumas formas de relevo que se encontram na Serra do Marão.

Assim, as rochas granitóides são responsáveis pelo elevado número de alvéolosque aí se desenvolvem. Independentemente da sua forma, do seu tamanho e da altitude a que se encontram, estas formas estão indubitavelmente ligadas aos diferentes tipos de granitos. Apesar destas rochas justificarem a sua génese (A. GoDARD, 1977), tivemos a oportunidade de demonstrar que eles se encontram relacionados com a existência de fracturas (A. PEDrosa, 1993) que, por um lado, facilitaram a meteorização da rocha, fenómeno que terá ocorrido fundamentalmente no final do Terciário (A. B. Ferreira, 1978; A. R. CORDEIRO, 1992) e, por outro, permitiram o posterior encaixe dos rios e alargamento dos vales.

Estas rochas são ainda responsáveis pela grande quantidade de "tors" que se encontram na área de Baião, mais concretamente na Serra da Aboboreira $e$, ainda, na parte mais oriental da área de estudo nos limites com a Serra do Alvão. Também em Vilar de Viandro (Mondim de Basto) estas formas aparecem sobre os granitos de Paradança (A. Pedrosa, 1993). Deste modo, são formas que não se relacionam particularmente com este ou aquele tipo de granito, mas antes pelo contrário com o modo como se processa a meteorização destas rochas, geralmente ao longo das diáclases, o que leva a que a parte interior dos blocos que definem seja a última a sofrer a acção deste processo. Quando se inicia o processo de exumação dos materiais dos mantos de meteorização fícam em saliência os blocos ou parte destes que não havia sofrido a acção da meteorização (C. T WIDALE, 1982, 1989; J. ROMANI, 1984).

Na Serra da Aboboreira foram também detectadas microformas dotipo vascas e caneluras eque evoluem sob as características do clima actual. A água que se acumula nestas formas pode exercer uma acção físicoquímica sobre determinados componentes do granito, nomeadamente sobre as micas e os feldspatos, que pode levar ao desenvolvimento e evolução destas formas.

Nos xistos surgem algumas depressões directamente relacionadas com a acção da tectónica.

A de maior dimensão é a depressão da Campeã e também a que se localiza a altitudes mais elevadas. Trata-se de uma depressão complexa onde é indesmentível a influência da tectónica na sua génese. Terá funcionado como um pequeno lago cujo fundo foi sendo progressivamente colmatado pela grande quantidade de materiais resultante da erosão das vertentes, transportados por pequenos cursos de água cujas bacias de recepção se situavam nas vertentes da depressão, ou chegados directamente através de solifluxões mais ou menos generalizadas. Pela análise das características do material aí depositado colocámos a hipótese da colmatação do lago se ter verificado devido a um grande afluxo de matérias durante 0 Tardiglaciar.

As outras duas depressões - Peso da Régua e Veiga - foram consideradas como pequenas fossas tectónicas, relativamente recentes, relacionadas com a fractura tardi-hercínica Orense-Bacia da Lousã.

Os quartzitos são rochas que pelas suas características de dureza têm normalmente reflexos importantes na morfologia (F. Rebelo, 1975). Em poucos locais da Serra do Marão estas rochas correspondem ao cimo das vertentes, situando-se, quase sempre, a meia encosta, relacionando-se, este facto, com problemasde ordem tectónica. Naturalmente que, quando encimam as vertentes, dificultam a acção dos agentes erosivos, pelo que, regra geral, correspondem às maiores altitudes. Noentanto, apesar de quase todo o afloramento quartzítico se encontrar a meia encosta e, por tal, se encontrar mais sujeito à dinâmica dos processos erosivos, contribuiu de forma indubitável para que os valores do declive dessas vertentes sejam sempre elevados e para que o seu processo de evolução seja mais lento. A tectónica, ao dobrá-los e ao fracturá-los, contribuiu para a vulnerabilidade que actualmente estas rochas apresentam aos diversos processos morfogenéticos (F. Rebelo, 1975, 1984). Só assim se compreende que em muitos locais sejam atravessados por pequenos cursos de água que exploraram fracturas, quer antigas, como acontece no caso do rio Teixeira, quer mais recentes, como acontece com a ribeira de Vila Cova que aproveita uma fractura de direç̧ão NNE-SSW, paralela ao acidente tardi-hercínico.

Masnem sóa litologia tem influência no desenvolvimento das formas de relevo. De facto, como já o vimos afirmando, a acção da tectónica é fundamental para a compreensão de algumas formas de relevo e, mesmo, para a formação da Serra do Marão. Sem dúvida que a orogenia hercínica foi a principal responsável pelo dobramento dos materiais do Ordovíciro e do Silúrico, assim como, pelo seu levantamento do fundo do oceano onde se tinha dado a sua deposição. Foi, ainda, durante esta orogenia que se verificou a intrusão das diversas rochas granitóides que se encontramna periferia da Serra. Este conjunto de movimentos orogénicos explicam muitas das fracturas e falhas que, ainda hoje, possuem reflexos na morfologia da área.

Apesar da importância que os movimentos hercínicos tiveram nesta área, as actuais formas de relevo relacionam-se com a actuação da orogenia alpina. Esta terá tido uma acção fundamentalmente epirogénica, que contribuiu para o soerguimento 
merain oc angra.

(S)

Sn

Q.n. 300000

$\hat{f}^{N}$

(m)

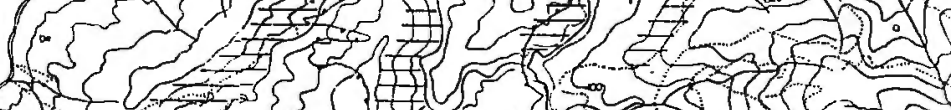
5 50 ,

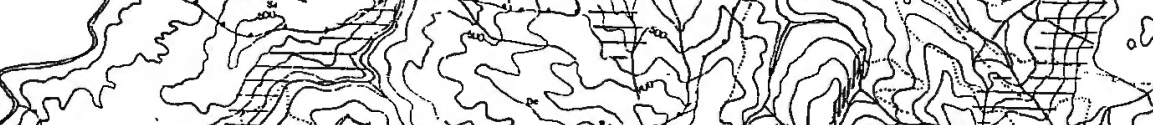
Sor (3) का 证

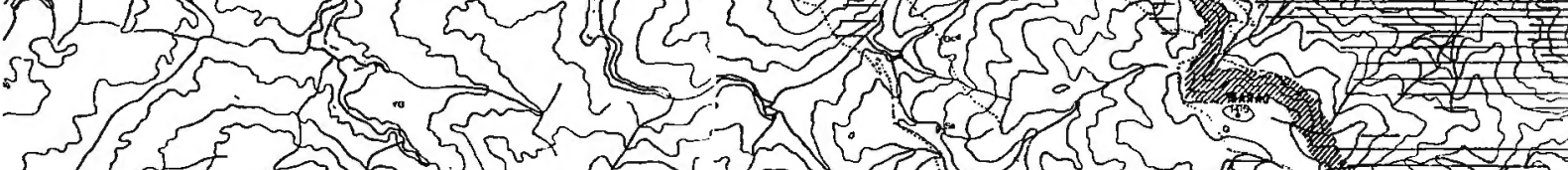
S

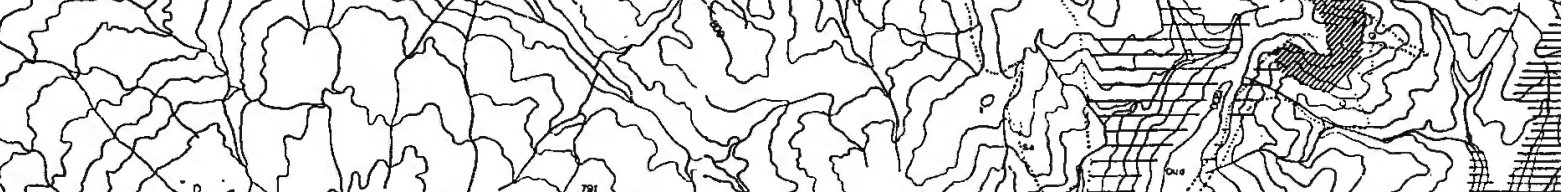
\{ 1) 3 tom ,

$\{3$, 3 , - 3 री

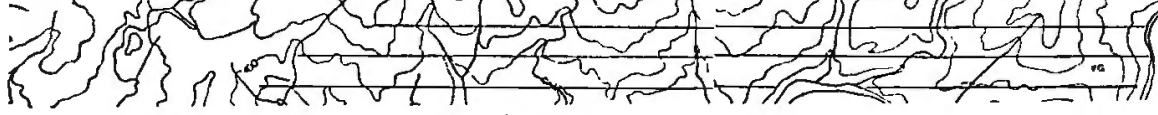



desta Serra em conjunto com a do Alvão. Assim, o conjunto montanhoso Marão-Alvão funciona como um horst, quer relativamente ao conjunto de depressões tectónicas onde se instalou o Rio Corgo, quer, ainda, relativamente ao graben do Tâmega. Na verdade, a acção desta orogenia ainda não deixou de se fazer sentir, pelo que a neotectónica continua a actuar sobre as actuais formas de relevo (A. RibEIRo, 1984; F. Rebelo e A. Pedrosa, 1993; A. Pedrosa, 1994) e como tal a modelar as formas de relevo, constituindo um risco permanente que o homem terá que ter sempre presente aquando das suas intervenções sobre o ambiente, nomeadamente na construção de infraestruturas rodoviárias ou de habitação.

Também a rede hidrográfica reflecte, de uma forma indubitável a influência da tectónica, salientandose três direcções fundamentais. A direcção NW-SE, que poderá reflectir antigas fracturas hercínicas que rejogaram recentemente, tem expressão significativa em toda a área da Serra do Marão, com particular realce na parte SW da mesma, onde predominam rochas granitóides. A direcçãoNNE-SSW, tradicionalmente considerada tardi-hercínica, observa-se na parte mais oriental da área de estudo, junto à fractura Orense-Bacia da Lousã. Pensamos que a orientação dos cursos de água segundo esta direcção reflecte a actuação da neotectónica, já que a fractura OrenseBacia da Lousã, é considerada como activa (J. CABRAL e A. R IbEIRo, 1989). Uma outra direcção (NE-SW) perpendicular à primeira poderá ser já o reflexo da orogenia alpina; esta direcção alinha cursos de água em toda a área da Serra do Marão, sendo de salientar o rio Tâmega e ainda troços finais dos rios Ovelha e Olo.

Para além destes dois importantes factores, também a influência que o clima exerceu é importante para compreender quer as formas actuais do relevo, quer a dinâmica morfológica actual.

A actuação dos diferentes processos morfogenéticos no passado só pode ser deduzida através dos vestígios que chegaram até aos nossos dias. Muitas vezes, esses vestígios são escassos até porque aqueles que actuaram num passado mais recente vão mascarando, e, por vezes, destruindo os indícios dos que haviam exercido a sua influência numa fase anterior.

A existência de alguns tipos de depósitos, nomeadamente os de vertente, permitiu inferir que os principais processos morfogenéticos responsáveis pela evolução das vertentes nos últimos tempos do Quaternário, na Serra do Marão, relacionam-se fundamentalmente com a acção do frio. Esta foi de tal modo importante que ainda hoje muitas vertentes apresentam-se regularizadas por material que resultou da fragmentação das rochas por crioclastia e muitos vales apresentam o seu fundo colmatado com depósitos que resultaram da evolução das vertentes onde os processos solifluxivos e mesmo gelifluxivos seriam dominantes. Os períodos de maior evolução das vertentes corresponderiam ao final do Pleniglaciar Wurmiano (20 000 a $18000 \mathrm{BP}$ ) e ao Tardiglaciar (11 000 BP) (A. Pedrosa, 1993). Mas, ainda em termos históricos, o frio poderá ter sido responsável pelo aparecimento de escombreiras de gravidade (A. Pedrosa, 1993, 1994). De facto, a Relação de Villa Real (1721) e seu termo, ao referir-se à freguesia da Campeã que fica "ao pé da alta e áspera Serra do Marão" afirma que "toda a terra he asperrima por muy penetrada dos rigores do frio, aonde existe neve a mayor parte do anno, e alguns até o mes de Agosto".

Para além de litologia, tectónica e paleoclimas, existe uma série de factores actuais que condicionam a dinâmica geomorfológica na Serra do Marão.

Naturalmente que o clima tem uma influência fundamental. O comportamento da precipitação numa determinada área é muito importante para a compreensão das morfodinâmicas actuais. Os quantitativos de precipitação anuais, apresentam-se elevados na área da Serra do Marão; no entanto, constatamos que a sua variabilidade espacial é nitidamente influenciada pela morfologia (S. Daveau, 1977; A. Pedrosa, 1993). A sua distribuição anual também é fundamental nas repercussões que possui nas morfodinâmicas actuais, já que existe um contraste forte entre os meses secos e aqueles em que se verifica maior quantidade de precipitação. Mas, mais importantes do que os quantitativos globais de precipitação e a sua distribuição ao longodo ano, são as fortes chuvadas que, por vezes, se verificam num espaço de tempo muito curto e podem ocorrer em qualquer época do ano. Todavia, a análise da ocorrência deste tipo de chuvadas torna-se difícil pois os registos de precipitação que existem, não especificam a duração temporal, já que são simplesmente diários. Apesar destes problemas, tivemos ocasião de analisar implicações geomorfológicas que algumas destas chuvadas tiveram, nomeadamente, na formação de ravinas e na ocorrência de deslizamentos (A. PEDrosa, 1991b, 1993).

Também o comportamento da temperatura ao longo do ano pode dar origem a determinados processos morfogenéticos. Nos locais onde se registam temperaturas negativas forma-se gelo o que pode conduzir à fragmentação das rochas se estas se encontrarem desprotegidas de solo e vegetação. A ocorrência de "pipkrakes" é outro fenómeno que está intimamente ligado às temperaturas negativas e cujas repercussões geomorfológicas tivemos a oportunidade de analisar.

O clima, apesar de influenciar fortemente a actuação dos processos morfogenéticos, por si só não os explica na sua totalidade (F. REBELO, 1981). De facto, é necessário ter em conta outros factores para determinarquais os que actuam numa determinada área e compreender o modo como contribuem para a 
evolução das formas de relevo.

Um outro factor importante para a compreensão das morfodinâmicas actuais é a cobertura florestal. A sua presença condiciona a escorrência, o impacto das gotas de chuva no solo, a formação dos "pipkrakes" e a acção do gelo. Assim, quando a vegetação não existe, a acção da escorrência adquire maior eficácia que será tanto maior quanto as vertentes apresentem fortes declives e existam depósitos que as regularizem.

A morfologia é outro factor a ter em consideração pois possui diversos tipos de implicações na dinâmica morfogenética de qualquer área. Na Serra do Marão, apesar das altitudes máximas não se apresentarem muito elevadas, já que apenas $9,5 \%$ se situam acima dos 1000 metros, verificamos que rapidamente se passa dos 50 metros (no vale do Douro) aos 1415 metros (vértice geodésico do Marão).

Este factor, além das implicações nos declives das vertentes, influi deforma notóriano comportamento de alguns elementos climáticos.

Assim, a temperatura terá tendência para um decréscimo rápido (principalmente no Outono e no Inverno) à medida que a altitude aumenta. Este comportamento tem diversos tipos de implicações, nomeadamente na cobertura vegetal da Serra, na formação de gelo e no aparecimento de "pipkrakes". Estes dois últimos fenómenos quando acentuados pelos efeitos de exposição das vertentes pode levar, na actualidade, à fragmentação das rochas e à movimentação dos calhaus nas escombreiras. No que concerne à biogeografia, o arrefecimento rápido que se verifica condiciona o desenvolvimento de diversos tipos de espécies vegetais. De facto, no espectrovegetal destaSerraénotório o desaparecimento das espécies arbóreas acima dos 900-1000 metros de altitude. Quando se verifica a sua existência, deriva da tentativa de reflorestação, que pode não ser bem sucedida se as espécies escolhidas não se adaptarem a determinadas condições climáticas de frio, de elevada precipitação, de ventos fortes e de condições edáficas.

A precipitação é outro elemento importante no estudo dos processos morfogenéticos e sobre o qual a morfologia tem grande influência quer na sua distribuição espacial, quer na sua quantidade e intensidade. $O$ facto desta Serra apresentar uma direcção geral NNE-SSW faz com que as massas de ar marítimo vindas dos quadrantes Oeste e Sudoeste, tenham uma subida rápida, originando precipitações elevadas nas partes mais altas. A análise deste elemento climático demonstrou que o posto udométrico da Campeã , que se encontra a 800 metros de altitude, é o que apresenta a precipitação média mais elevada. Ocomportamento anual deste parâmetroé fundamental para a compreensão de alguns processos morfogenéticos. Mas talvez mais importante que a distribuição anual é o facto da maior parte da precipitação anual que se verifica, ocorrer em dias com mais de $10 \mathrm{~mm}$ de precipitação. Nalguns postos udométricos, como por exemplo a Campeã, a precipitação, que ocorre em dias com mais de $40 \mathrm{~mm}$, assume importância fundamental, pelo que, mais uma vez, a altitude parece exercer uma acção significativa no aspecto que acabamos de referir, apesar da análise realizada não se mostrar tão linear. Naturalmente que a concentração da precipitação em dias com mais de $10 \mathrm{~mm}$ repercute-se na dinâmica de alguns processos morfogenéticos, nomeadamente, na acção da escorrência e do "splash", principalmente se o solo se encontrar desprotegido de vegetação.

Apesar de toda a importância que estes factores têm nas morfodinâmicas actuais, estas não podem ser comprendidas se não tivermos em atenção a actuação do homem sobre o ambiente. $O$ homem, com a capacidade de intervenção que possui, pode modificar completamente a dinâmica morfogenética de qualquer área. Deste modo, torna-se cada vez mais premente estudar a maneira como hoje se processa a sua acção, naturalmente sem esquecer o passado, para determinarmos, por um lado, os riscos a que o ambiente está sujeito e, por outro, os riscos que ele próprio corre. Os riscos não podem ser desconhecidos, têm de ser completamente assumidos.

\section{O homem como factor e agente na morfogénese actual}

O homem, no entanto, tem cada vez maior influência como factor e agente interveniente na actuação dos processos morfogenéticos (F. REBELO, 1977; R. Neboit, 1979, 1991; R. Neboit et al., 1984; J. ZEZzere, 1988; J. Garcia-Ruiz et al., 1990; A. Pedrosa, 1991 b, 1993, 1994; A. Pedrosa et al., 1992). A sua actuação pode inserir-se na dinânica do ecossistema de que faz parte, ou pode assumir um papel de ruptura do equílibrio ambiental existente, modificando o dinamismo dos processos erosivos. Em casosmais extremos pode provocaro aparecimento de outros processos que não existiriam se apenas se considerasse a dinâmica natural da área. É lamentável, mas, na verdade, o homem tem quase sempre um efeito de rompimento do equilíbrio dinâmico das forças da natureza. Todavia, o seu poder de consciencialização dos problemas pode levar a que a sua actuação seja no sentido de recuperar o equilíbrio natural ou, pelo menos, minimizar os efeitos da sua actuação (J. BETHEMONT, 1987).

A suaacção tornou-se particularmente destruidora durante o século actual, tendo como principal causa a pressão demográfica que o obrigou a uma exploração mais profunda dos recursos naturais. Este problema levou-oà utilizaçãode técnicas cada vezmais agressivas 
no intuito de retirar o maior rendimento possível do meio físico, sem qualquer preocupação com as consequências que, eventualmente, possam ter na dinâmica dos diferentes processos morfogenéticos e, mesmo, na dinâmica global do ecossistema (A.N. S TRAHLER, A. STRALHER, 1973; D. DREW, 1983; J. BETHEMONT, 1987).

A prática da agriculturaé desde tempos imemoriais uma actividade que vem acompanhando a vida do homem tendo repercussões importantes na paisagem, que podem ser mais ou menos violentas de acordo com as técnicas utilizadas e o carácter intensivo com que se praticam (R. Nebort, 1980; S. DAVEAU, 1980; H. B RUCKNER, 1986).

O homem tanto ocupa os fundos de vale e depressões, como algumas vertentes, por vezes, com declives superiores a 181/2. Se nos fundos dos vales e das depressões as alterações que o homem introduziu não são muito significativas, o mesmo já não se poderá dizer das vertentes. O perfil destas sofreu fortes modificações, devido à construção de socalcos com muros de suporte, em pedra. Esta é uma das técnicas, mais comuns e tradicionais que o homem utiliza para o seu aproveitamento, quer na Região Demarcada do Douro (A. PEDRosA, 1993 b), quer nas regiões de agricultura tradicional. Muitas vezes, os socalcos coincidem com locais onde as vertentes se encontram regularizadas por materiais resultantes da sua evolução quaternária, que permitem a existência de um solo com capacidade agrícola.

Apesar das modificações que provoca nos perfis das vertentes, a construção de socalcos é uma das técnicas mais eficazes para evitar a erosão dos solos, em áreas de declive muito forte, mesmo na fase em que se encontram lavradas, altura em que o impacto das gotas da chuva e a água de escorrência podem exercer uma maior acção erosiva podendo surgir ravinamentos. No entanto, esta técnica favorece fundamentalmente o processo de infiltração já que altera radicalmente o perfil das vertentes e cria plataformas cujo declive se aproxima dos $01 \frac{1}{2}$. Deste modo, nas vertentes onde se pratica a agricultura em socalcos, verifica-se um acréscimo substancial de água que se infiltra pelo facto do perfil natural da vertente ter sido completamente modificado. Nas áreas de agricultura tradicional, constata-se que a rega por gravidade das culturas nos meses de Verão é uma prática comum. Esse facto vai também contribuir para que se verifique uma certa infiltração em alturas em que não era normal que ocorresse. A prática da rega coincide com os meses de temperaturas mais elevadas, peloque o processo de meteorização química pode acelerar-se.

Ainda em relação com estas áreas, podem surgir movimentos de massa que se explicam pela forte meteorização das rochas e, mesmo, pelas técnicas que o homem utiliza para a retenção das águas que depois vai utilizar na rega. Podemos citar como exemplo o movimento de terras que ocorreu em Santa Maria do Zêzere (Baião) em 2 de Março de 1985; numa área de socalcos, verificou-se um movimento envolvendo centenas de toneladas de terra e pedra pela encosta abaixo, arrastando árvores, devastando vinha existente no local vindo a obstruir a estrada que serve as localidades de Santa Marinha do Zêzere e limítrofes (JN 8/3/85).

Pela análise do local onde ofenómeno decorreu e pelo contacto com os populares que conheciam bemo local, pode afirmar-se que o processo verificado é muito idêntico àquele que, em 1981, aconteceu em Arosa (A. Pedrosa et al., 1992). Inicia-se por um deslizamento rotacional, passando depois a uma típica escoada de lama com calhaus e blocos.

$O$ desencadeamento do processo verificou-se na sequência de alguns dias de chuva contínua. Mas a existência de uma pequena represa, feita $\mathrm{em}$ moldes tradicionais, imediatamente a montante do local onde se verificou a ruptura, poderá ter contribuido para o desencadeamento do processo, já que permitiu uma maior quantidade de infiltração de água nos terrenos envolventes. Todos estes factos conjugados levaram a que se verificasse a ruptura do equilíbrio da vertente.

Nos locais onde foi imperiosa a mecanização de alguns processos de trabalho, para se obter uma maior rentabilização das explorações, nomeadamente na Região Demarcada do Douro, modificou-se a maneira de actuar tradicional do homem sobre as vertentes. Aqui, introduziram-se novas técnicas, nomeadamente o plantio da vinha, segundo as curvas de nível (M. CuNHA, 1991), que nãoé senão a adaptação do plantio da vinha "a eito" (J. ALMEIDA, 1990) à mecanização que esta cultura sofreu a partir da década de sessenta. Recentemente, a técnica mais utilizada é a construção de patamares, mesmo em áreas de declive superior a 251/2 (BIANCHI DE A GUIAR, 1985) que suportam um ou dois alinhamentos de cepas. Esta técnica, para além de mais agressiva para a manutenção do equilíbrio dinâmico das vertentes, permite uma acção muito violenta de alguns processos erosivos, nomeadamente o "creep" e odesenvolvimento de ravinamentos, e 0 aparecimento de deslizamentos que nas técnicas mais tradicionais não ocorriam com tanta frequência. A própria técnica em si leva muitas vezes à fragmentação da rocha contribuindo deste modo para o incremento da meteorização física. Foi possível observar, em Setembro de 1990, durante uma fase de trabalho de campo, movimentos de terra num local próximo de Mesão Frio (Vila Marim), mas a sua ocorrência, apesar de se relacionar com forte precipitação, deveu-se principalmente à acção do homem. Este, com o intuito da renovação de uma antiga vinha, destruiu os socalcos, antigos, suportados 
por um muro de pedra, tendo aberto patamares sem qualquer preocupação de protecção do talude que este tipo de técnica origina. Deste modo, verificouse um remeximento muito grande de todo o terreno, numa vertente com cerca de $151 / 2$ de declive. Após alguns dias de chuva verificou-se neste local uma série de deslizamentos, desmoronamentos e ravinamentosque destruiu completamente todoo investimento que havia sido realizado.

Em Dezembrode 1992, verificaram-se novamente movimentações de terras na Região Demarcada do Douro, relacionadas com a armação de terreno em patamares para a plantação da vinha. $O$ caso mais espectacular terá sido feito na preparação do terreno e na plantação da vinha, provocado pelos pequenos deslizamentos e pelos ravinamentos que ocorreram (Fot. 1), mas também porque a acumulação de terra e blocosna linha férrea provocaram o descarrilamento de um comboio.

Graças a estes problemas tem-se vindo a testar uma nova técnica de armação de terreno para plantação de vinha "alto" que nãoé mais do que a plantação da vinha segundo o maior declive de vertente (M. CUNHA, 1991). No entanto, também surgem alguns problemas de erosão, principalmente após o remeximento do terreno para a plantação das cepas. Os processos com maior dinamismo são, então, o "creep", o "splash" e a formação de ravinas (A. PEDrosa, 1994).

Não restam quaisquer dúvidas de que a construção de socalcos com muro de suporte em pedra era a técnica mais eficaz na luta contra a erosãodas vertentes, apesar de favorecerema infiltraçãoe consequentemente facilitarem o desabamento dos muros de suporte, principalmente $\mathrm{em}$ alturas de chuvas prologadas. A sua reconversão para a mecanização mostra-se extremamente dispendiosa, pelo que se procuram outras técnicas em que o investimento inicial seja menor, mesmo quando já foram reconhecidos os seus aspectos negativos, até na própria qualidade do vinho (J. ALMEIDA, 1990).

Mas a prática da agricultura, nãoé a única forma de o homem actuar sobre o ambiente, já que as outras actividades por ele desenvolvidas também podem reflectir-se na dinâmica ambiental. Assim, a pastorícia é ainda uma prática comum nas vertentes da Serra do Marão e faz-se especialmente com gado caprino, apesar de se verificar também com gado bovino.

Não é muito comum a existência de prados preparados pelo homem para servirem de pastagem. A pastorícia faz-se, fundamentalmente, em áreas de pastagem espontânea, correspondendo quase sempre a áreas de forte declive e de altitude elevada (superior a $700 \mathrm{~m}$ ), onde nãoé possível a prática da agricultura, nem a sua utilização para o aproveitamento florestal.

A prática da pastorícia tem diversos tipos de implicações que podem ser importantes pela sua interferência sobre a dinâmica dos processos morfogenéticos.

Quer a pastorícia seja feita com gado caprino, quer seja com gado bovino, ela vai repercutir-se na área, na medida em que se verifica uma selecção de plantas, desenvolvendo-se com mais facilidade aquelas que os animais rejeitam, levando a modificações, por vezes importantes, na composição florística da Serra.

A pastorícia conduz, em última análise, à rarefacção da cobertura vegetal $e$, portanto, ao aparecimento de espaços vazios, que ficam sujeitos a um maior impacto de outros agentes erosivos (T. Muxart et al., 1990; R. Neboit et al., 1990).

Saliente-se ainda que, devido à prática desta actividade, se assiste, com frequência, à utilização da técnica do fogo, nas queimadas que se fazem para
Fot. 1 - Movimentaçães de terras provocadas pelos temporais de Dezembro de 1992 (Godim. Peso da Régua).

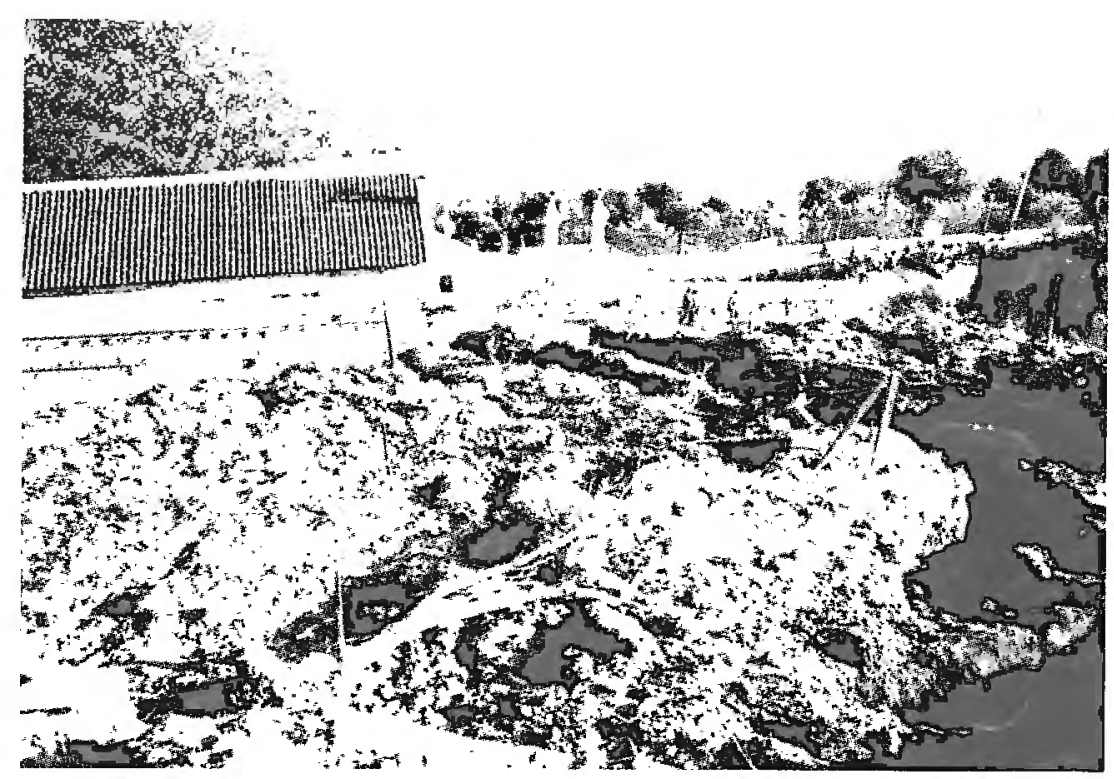


se conseguir novas regenerações das plantas. Por norma, o fogo é ateado à vegetação sub-arbustiva e arbustiva durante os meses de Verão ou já no fim desta estação, para que na Primavera seguinte se inicie mais cedo o processo de crescimento e/ou regeneração das plantas de modo a poderem ser utilizadas pelos animais na sua alimentação. Deste modo, durante o Outono e o Inverno a vertente fica sujeita a uma morfodinâmica mais intensa por parte de determinados processos que, por vezes, levam ao aparecimento de problemas erosivos graves, principalmente quando se utiliza esta técnica várias vezes, num curto período de tempo. Saliente-se o incremento da acção da escorrência e do "splash". A sua constante repetição pode iniciar um processo de "desertificação" de determinadas áreas devido à erosão do solo, já de si esquelético, e o aparecimento da rocha à superfície. Alguns locais da vertente ocidental desta Serra, mais concretamente na área de Pardelhas, denotam alguns sinais de rarefacção espacial das espécies vegetais, devido ao desaparecimento do solo, relacionado com vários incêndios que aqui ocorreram. Quando as áreas se encontram a altitudes superiores a $1000 \mathrm{~m}$ e a rocha passa a aflorar à superfície, ela passa a sofrer a acção do gelo/degelo verificando-se a sua fragmentação através da crioclastia como acontece nas cabeceiras da ribeira de Chão Rosso (A. PEDrosa, 1994).

Oreflorestamento que se verificou neste século foi outro fenómeno que alterou substancialmente a dinâmica geomorfológica da Serra do Marão. De facto, a plantação de espécies florestais numa área em que tradicionalmente dominava um espectro arbustivo ou mesmo sub-arbustivo leva à modificação dos processos que actuam nas vertentes em que se fez plantação. O impacto das gotas da chuva passa a ter pouco significado assim como a escorrência. A infiltração, pelo contrário, passa a assumir um papel fundamental, contribuindo para a meteorização da rocha "in situ".

O primeiro reflorestamento, que se verificou nas décadas de quarenta e cinquenta, foi na sua maior parte completamente destruído pelo grande incêndio de 1985, que modificou totalmente o espectro vegetal da Serra do Marão, que em 1989 se apresentava dominado novamente pelas espécies arbustivas e herbáceas. Nesta altura tinha-se iniciado um novo programa de reflorestamento desta Serra, o qual se encontra ainda numa fase inicial, razão pela qual não se representam no mapa junto as áreas preparadas para a reflorestação.

Se as técnicas utilizadas na plantação das espécies florestais não forem as mais adequadasàs características do local entendidas como características topográficas, edáficas, litológicas, climáticas, morfológicas, podem ocorrer diversos tipos de implicações geomorfológicas.
Fundamentalmente, são duas as técnicas que se empregam na área da Serra do Marão: a construção de patamares e a plantação individual das espécies através da abertura manual de covas. Esta última é, naturalmente, a mais adequada já que tem menos implicações na activação dos processos erosivos. A armação do terreno em patamares, para além de extremamente agressiva, no que se refere à destruição do solo natural e à fragmentação da rocha, também modifica a evolução geomorfológica da vertente. Assim, o trabalho das máquinas, ao abrir os sulcos nas vertentes, vai destruir o solo (quando existe) e fragmentar a rocha "in situ". O remeximento do solo e a fragmentação da rocha facilitam a movimentação dos materiais ao longo das vertentes, podendo levar ao aparecimento de ravinamentos. Também o impacto das gotas da chuva passa a ter maior poder erosivo e o transporte dos materiais pela água de escorrência é facilitado, principalmente no que se refere aos elementos de menor dimensão, podendo levar ao aparecimento de ravinas. Do mesmo modo, os movimentos lentos podem ser incrementados, nomeadamente o "creep". O aumento da importância deste fenómeno é compreensível atendendo a que os materiais ficam soltos e, portanto, mais sujeitos à movimentação.

Pode-se exemplificar com a movimentação em massa que se verificou próximo do marco geodésico de Cabeço (833 $\mathrm{m}$ ), entre as povoações de Paradela do Monte e Póvoa da Serra, já que está nitidamente relacionada com a actuação do homem nas vertentes. Assim, nas cabeceiras de um afluente dorio Aguilhão, o homem remexeu o solo e fragmentou a própria rocha para construir patamares para a plantação de pinheiros, numa vertente que apresntava um declive médio da ordem dos $251 / 2$. O trabalho não teve qualquer respeito pelas linhas naturais de escoamento das águas, nem a preocupação de construir um sistema de drenagem eficaz, no sentido de controlar as águas de escorrência. Eis a razão porque se verificou a desorganização da rede de drenagem natural e a formação de ravinamentos nos taludes construídos, o que teve comoconsequência uma grande movimentação de terras que desceram ao longo do talvegue natural, tendo contribuído para o aprofundamento do mesmo.

Para além destes aspectos importantes em termos de dinâmica geomorfológica, há um outro para o qual importa chamar a atenção e que se relaciona com aspectos climáticos locais.

Em inquérito realizado na Campeã, as pessoas mais idosas são unânimes em afirmar que actualmente o clima é "menos duro" do que antigamente. Esta referência tanto é feita para o Inverno como para o Verão. Asseguram que os Invernos são menos frios e os Verões menos quentes e que esta tendência se começou a operar com o reflorestamento e crescimento da floresta. Lamentavelmente não existem dados 
quantitativos que corroborem estas informações, mas pensamosque era interessante deixar este apontamento, até porque este poderá ser um dos impactos da reflorestação de grandes áreas. Declaram, inclusivamente, que a queda de neve é menos frequente e em menor quantidade do que aquela que se verificava antes dos reflorestamentos, facto de difícil comprovação nos registos da estação meteorológica de Vila Real, dada a irregularidade da queda de neve na cidade, que se encontra a altitudes muito inferiores (400 a $500 \mathrm{~m}$ ) à Serra do Marão, que possui aproximadamente 9,5\% da sua área acima dos 1000 metros.

Uma outra actividade que se fez sentir com intensidade e cujos impactos no ambiente foram, geralmente, agressivos, foi a exploração mineira.

Actualmente, funcionam apenas dois tipos de explorações: a exploração de xistos ardosíferos landeilianos, próximo de Mascoselo (freguesia de Vila Cova), para utilização na construção civil, e a exploração de quartzitos ordovícicos e metagrauvaques, para " brita", junto às antigas minas de magnetite de Vila Cova. No entanto, nas décadas de quarenta, cinquenta e sessenta, existiu um número elevado de explorações mineiras relacionadas com a extracção de diversos tipos de minérios (ferro, volfrâmio, etc), para a utilização em fins industriais.

Para o presente trabalho não interessa propriamente o tipo de exploração a que as pessoas se dedicavam, mas antes, as consequências ambientais que daí advieram ou ainda advêm.

As explorações de ferro foram feitas através de minas e o seu abandono pode originar eventuais abatimentos, apesar de, até ao momento, não se ter conhecimento de qualquer ocorrência. As cascalheiras resultantes da extracção dos diversos minérios são uma outra consequência ambiental. Raras vezes se encontram em equilíbrio com a vertente pois o declive que apresentam é superior ao desta. Podem citar-se como exemplo as escombreiras das minas de Freitas, de Aboadela e de Vila Cova, entre outras. São formas funcionais que é necessário ter em consideração no ordenamento do território, quer pela sua localização, quer pela sua dinâmica, a fim de evitar qualquer tipo de risco (L. FAUGERES, 1991). Por vezes, a exploração de alguns recursos minerais faz-se a céu aberto, o que, para além das consequências paisagísticas que daí advêm, podem levar ao aparecimento de outros processos, nomeadamente, o aparecimento de ravinas como aconteceu na área de Muas (A. Pedrosa, 1993).

A construção de infra-estruturas, fundamentais à vida actual do homem é também um factor de modificação no ambiente. Dentro deste tema, talvez a construção de estradas e caminhos rurais tenha maior impacto, em especial devido à construção de barreirase taludes artificiaise, ainda, pelas interferências que se verificam na dinâmica dos cursos de água.
O aparecimento de barreiras e taludes artificiais interfere na dinâmica dos processos morfogenéticos, podendo fazer surgir alguns e acelerar outros ( $F$. REBELO, 1977), nomeadamente, casos de ravinamentos e pequenos deslizamentos e, mesmo, de alguns desmoronamentos.

Existem vários exemplos podendo começar por referir aqueles que ocorrem nos taludes da IP 4 que, por vezes, podem afectar a própria estrutura da estrada (A. PEDrosa, 1993). De facto, várias foram as ravinas (Fot. 2) que surgiram directamente relacionadas com a concentração da escorrência muitas vezes provocada pelas deficientes infra-estruturas construídas para canalizar as águas da chuva. Frequentes são também os deslizamentos principalmente quando o tipo de chuva favorece a infiltração e satura as camadas mais argilosas.

A própria abertura de caminhos florestais pode desencadear ravinamentos (Fot. 3). A título de exemplo, durante o Verão de 1992 aconteceu um fenómeno deste tipo numa vertente próximo da povoação de Paradela do Monte (concelho de Santa Marta de Penaguião). A vertente havia sofrido em Julho de 1991 um incêndio que destruiu a sua cobertura florestal. É uma vertente com um declive na ordem dos $301 / 2$

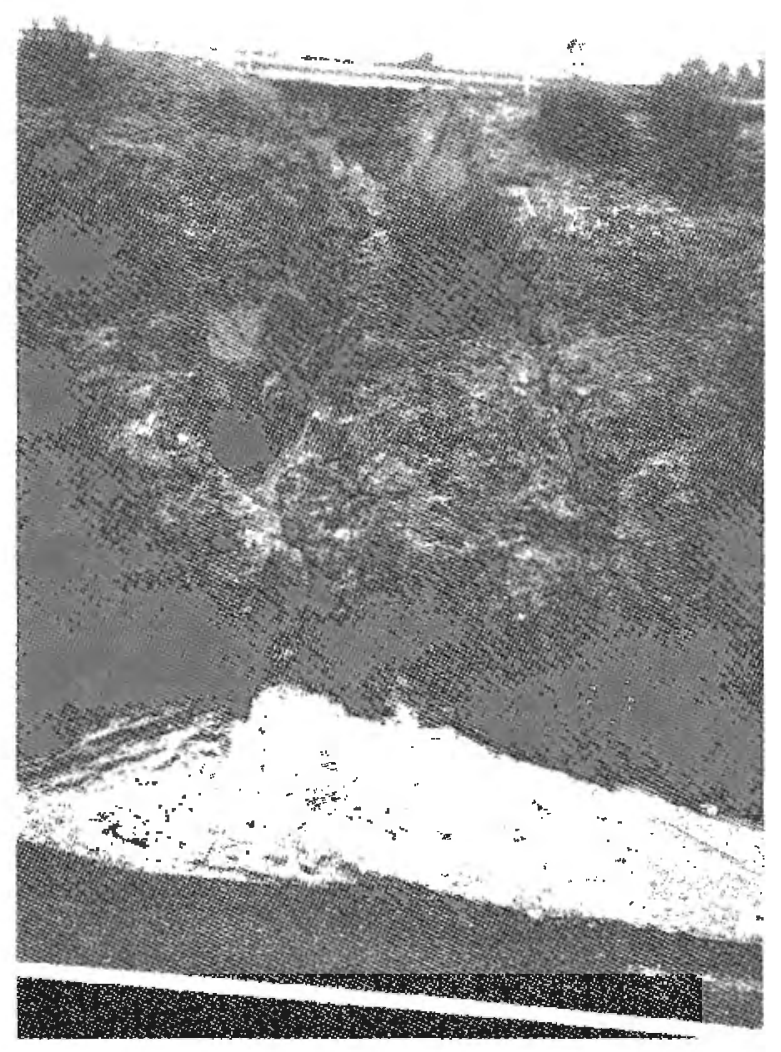

Fot. 2 - Ravinamentos em taludes da IP 4 (Padronelo, Amarante). 


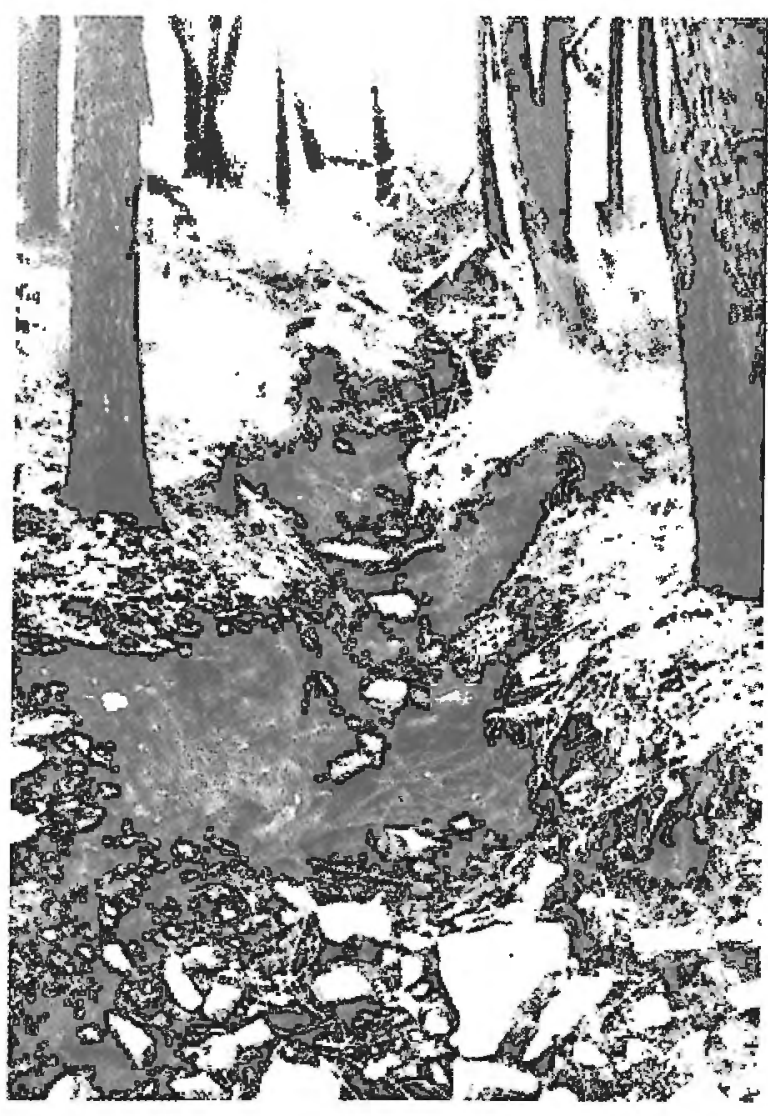

Fot. 3 - Ravinamento desencadeado por chuvas intensas no Verão de 1992 em área ardida um ano antes (Paradela do Monte).

completamente regularizada por depósito. Sensivelmente a meio, o homem abriu caminhos florestais onde instalou uma canalização para transporte de água.

Em Julho de 1992, verificou-se uma forte chuvada no local em questão que não terá demorado mais de uma hora. Numa primeira fase, a água de escorrência orientou-se por um dos caminhos existentes ravinandoo. Numa segunda fase, o escoamento deixou de se processar pelos caminhos inflectindo no sentido do maior declive da vertente originando duas ravinas. Uma, aprofundou um barranco preexistente enquanto a outra, no início, se desenvolveu lateralmente a um pequeno valeiro existente na vertente, aproveitandoo apenasna fase terminal aprofundando-lhe o talvegue. O seu início está relacionado com a concentração de água na confluência dos dois caminhos existentes.

Nosentido de se calcular a quantidade de material que as duas ravinas ali mobilizaram fizeram-se algumas medições. Assim, mediu-se o seu comprimento e, ainda, a largura e a profundidade em algumas secções. Em função dessas medições, calculou-se a quantidade de material mobilizado. Para a ravina $\mathrm{n}^{0} 1$ esse valor seria da ordem dos $465 \mathrm{~m}^{3}$ enquanto para a ravina $\mathrm{n}^{\circ} 2$ o valor se apresentava superior, rondando os $570 \mathrm{~m} 3$. Toda esta quantidade de material terá sido deslocada apenas durante o pequeno período em que ocorreu a forte chuvada.

Também a queda de blocos pode surgir após a abertura de estradas ou caminhos rurais. Com a abertura do Itinerário Principal $n^{\circ} 4$ (IP 4), constatouse o início de quedas de calhaus e blocos ao longo de algumas barreiras desta estrada. A queda verifica-se porque as barreiras apresentam um declive muito acentuado (na ordem dos $751 / 2$ ou mais) sofrendo os blocos a acção muito forte da gravidade. Os locais, ao longo desta infra-estrutura, onde a queda de blocos e calhaus ocorre com a maior intensidade, estão directamente relacionados com aqueles onde se verifica a formação de gelo com maior frequência, durante o Inverno. Deste modo, pensamos que a actuação dos diversos ciclos gelo/degelo tem forte influência neste processo.

Também nas estradas secundárias e nalguns caminhos florestais este processo pode acontecer, principalmente quando se encontram em locais de altitude superior a 800 metros.

Os desmoronamentos também podem ocorrer devidoà construção de estradas e mesmo de caminhos de ferro. Pode-se começar por referiro que se passou na Estrada Nacional $\mathbf{n}^{\circ}$ 2, próximo da povoação da Cumieira em Dezembro de 1989, que tivemos a oportunidade de observar. Devido à elevada precipitação que se registou antes do dia 18 , altura em que se verificou o desabamento, e ao facto dos esgotos pluviais se encontrarem completamente obstruídos por falta de limpeza dos canais de escoamento, verificou-se a infiltração da água por outros locais, o que levou à queda do muro de suporte e de parte do piso da estrada (Fot. 4).

O desmoronamento de muros de suporte, quer de suporte de socalcos, quer de estradas, é algo que ocorre com certa frequência, até porque o seu número nesta área é muitoelevado atendendo às características topográficas. A ocorrência relaciona-se, quase sempre, comquantidades de precipitação elevadase verificadas ao longo de vários dias e com o facto da infiltração nos socalcos ser favorecida, como já afirmámos.

Por vezes, estes processos não são simples intervindo a actuação de vários fenómenos pelo que é difícil a sua classificação. Podemos começar por referir o ocorrido na Campeã em Julho de 1987. De facto, uma forte trovoada acompanhada da queda de enormes pedras de granizo, verificou-se aí, no dia 6 de Julho, cerca das 18 horas (JN 8/7/87). As culturas foram então muito danificadas devido à invasão dos campos por grandes amontoados de terra e pedras arrastados pelas chuvas torrenciais. Também nas estradas eram visíveis sinais inequívocos da tempestade pois estas encontravam-se cobertas por lama e pedras. 


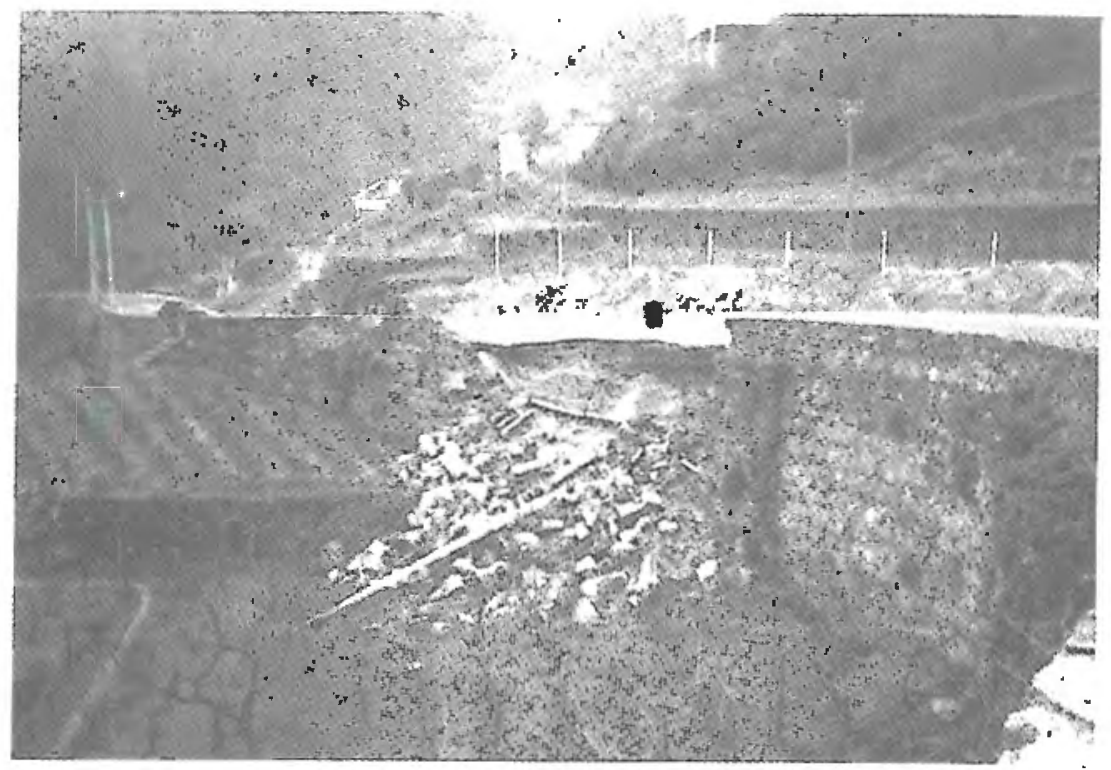

Fot. 4 - Desmoronamento ocorrido na EN 2 pertode Cumieira na sequência dos temporais de Dezembro de 1989.
Os caminhos rurais de terra batida ficaram intransitáveis. A acumulação de lama nal guns sítios e os sulcos que se desenvolveram dificultavam a passagem.

Pelo testemunho de uma pessoa entrevistada parece que este problema se deveu, em parte, ao facto de na altura estar a ser construído um lanço do Itinerário Principal $n^{\circ} 4$ (IP 4). Segundo as suas proprias palavras, toda a enxurrada de lama e pedras foi arrastada para a Campeã "pois a estrada nova que estão a abrir (IP 4) concentra a água que deixa os seus leitos naturais e vem assim de enxurrada levando tudo na frente" (J.N. 8/7/87).

Conhecidos, são os desabamentos das barreiras de linhas férras portuguesas. Uma das mais afectadas é a linha do Douro. De facto, são frequentes as notícias de movimentos de terras e queda de pedras das barreiras nesta linha, no que se refere à parte inserida na área de estudo.

Recuandono tempo, como exemplo, pode lembrarse que, em 1960 (PJ 20/11/60), entre as estações de Aregos e Mosteirô, um comboio de mercadorias chocou com um grande pedregulho que havia caído sobre a linha, descarrilando a locomotiva e sete vagões, perdendo-se grande parte da carga de vinho. Segundo a notícia então publicada, "a queda do bloco arrastou grande volume de terras que obstruiu a linha férrea" (PJ 20/1 1/60). Ou ainda a datada de $26 / 6 / 62$ onde se refere que uma forte chuvada levou à interrupção da circulação dos comboios na linha do Douro entre Porto de Rei e Barqueiros. Para além dos prejuízos causados nas vinhas e nos campos de cultivo, "as enxurradas precipitaram-se de tal modo sobre a linha que os carris ficaram torcidose desapareceu a brita em que assentavam. Tudo foi levado não sem que a via férrea desaparecesse em vários troços, completamente coberta pelas pedras que desabaram do alto das trincheiras que a marginam" (J.N. 26/6/ 62). Esta descrição demonstra como estes movimentos de terra podem ser complexos misturando-se a actuação de diferentes processos que podem ser a movimentação individual de partículas, a queda de blocos e movimentações de massa, lentas e rápidas.

Todos estes processos se relacionam com fortes precipitações, muitas vezes durante um período prolongado, acabando a infiltração por saturaro solo e provocar este tipo de fenómenos. No entanto, não podemos esquecer que é a acção do homem que modifica as condições naturais e, como tal, altera toda a dinâmica da área contribuindo para o seu aparecimento.

Podem ainda verificar-se interferências na dinâmica fluvial que se prendem fundamentalmente com o estrangulamento dos vales, já que a abertura que se deixa para a passagem da água é calculada para um caudal normal, sem ter em atenção a possibilidade de cheias anormais. Nos cursos de água esporádicos, nem com este facto se tem tido grandes preocupações. Assim, quando ocorre uma forte chuvada, seguem-se, muitas vezes, grandes enxurradas, com capacidade para transportar materiais sólidos de diversas dimensões, o que pode levar ao entupimento dessas passagens. As consequências que daí advêm são diversas. A menos grave talvez seja a passagem da água e dos materiais por cima da estrada, como aconteceu na Cumieira em 1989 (A. Pedrosa, 1990). Mais grave do que isso poderá ser o cortar de parte da estrada ou do caminho rural, como aconteceu em 8 de Dezembro de 1992 na estrada que liga Campeã a Fontes, um pouco antes da povoação de Cotorinho (freguesia de Campeã). 
Neste local, o curso de água apresenta uma queda. Devido à elevada quantidade de precipitação que se verificou nesse dia, ocaudal do curso de água aumentou, arrastando consigo grandes quantidades de material que se encontrava no fundo do talvegue associado àquele que entretanto havia aí chegado resultante da zrosão que as vertentes nessa altura sofreram. $\grave{A}$ grande quantidade de material rochoso, juntaram-se, ainda, alguns troncos deárvores arrancadas às vertentes. Toda esta quantidade de material bloqueou a passagem que o homem havia construído para que o caudal normal deste pequeno curso de água circulasse por baixo da estrada. Por estes factos e pela própria violência da enxurrada na altura, a estrada naquele local foi arrastada e incorporada no material que o rio transportava, à semelhança do que aconteceu na estrada Coja-Esculca, na Cordilheira Central, que sofreu um corte provocado pela ribeira de Vale Monteiro logo após as primeiras chuvas que se verificaram a seguir aos grandes incêndios do Verão de 1987 (L. LOURENÇO, 1988).

A construção de casas pode também ter alguns impactos geomorfológicos. Actualmente, quando se constroi em vertentes de declives muito fortes como os existentes na Serra do Marão - faz-se uma terraplanagem que implica a criação de taludes e barreiras artificiais nas vertentes. Deste modo, a dinâmica natural é modificada e podem acontecer situações como a que ocorreu na Cumieira onde num desses taludes, na sequência de uma forte chuvada, se desenvolveram rapidamente ravinas com sete metros de comprimento (A. Pedrosa, 1991, 1993). Este processo não demorou mais de 30 minutos, ou seja, o tempo que levou a chuva a cair (J.N. 6/8/89).

\section{Conclusão}

A actuação recente do homem sobre o ambiente faz-se, quase sempre, de um modo agressivo, contribuindo para a sua degradação e pondo, por vezes, em risco as suas próprias actividades e, porque não, a sua própria vida. Este tem que tomar consciência dos riscos inerentes à sua acção (L. FAUGÈRES, 1991) para evitar situações de perigo trabalhando de uma forma correcta e, deste modo, tirar o máximo partido dos recursos que a natureza lhe oferece. É necessário deixar de pensar de uma forma imediatista, ditada por princípios meramente economicistas. Importa que a utilização e a exploração que o homem actualmente faz dos recursos naturais não seja para a obtenção de lucro fácil aproveitando ao máximo os recursos e os investimentos feitos, para se começar a pensar em investimentos a longo prazo, cujas consequências não sejam tão nefastas para a natureza e para as gerações futuras.

\section{BIBLIOGRAFIA}

ALMEIDA, J. ( 1990) - "Vitivinicultura duriense: contributo para uma actualização". Observatório, V. N. de Gaia 1, p. 17-30.

Bethemont, J. (1987) - Les richesses naturelles du globe. Paris, Masson.

B IANCHI-AgUiAR, F. (1985)- O terraceamento em viticultura, traduçã̃o das conclusŏes de Michalsky, DFER, UTAD, Vila Real.

BiANCHI-AgUiAR, F. (1987)- Cultura davinha em terrenos de encosta - alternativas para a sua implantação, DFER, UTAD, Vila Real.

BRUCKNER, H. (1986) - "Man's impact on the evolution of the physical environment in the mediterranean region in historical times". Geo Joumal, p. 7-17.

Cabral, J.; Ribeiro, A. (1989) - Carta Neotectónica de Portugal: Nota explicativa. Escala de 1/1 000000 . Serviços Geologicos de Portugal, Lisboa.

CORDEIRO, A. M. ROCHETTE (1992) - "Alvéolos graníticos do CentroNorte de Portugal. Génese e tipologia". Actas do VI Colóquio Ibérico de Geografia, Porto (no prelo).

ClNha, M. CAMPos (1991) - Contribuiçäo para a determinação dos custos de implantação de vinha na Região Demarcada do Douro, ADVID, Peso da Régua.

DAVEAU, S. (1977) - Repartition et rythme des précipitations au Portugal. Memorias, $n^{\circ} 3$, Lisboa, C.E.G.

Daveau, S. (1980) - "Espaço e tempo. Evolução do ambiente geográfico de Portugal ao longo dos tempos pré-históricos". Clio-Revista do Centro de História da Univ. de Lisboa, Lisboa, p. 13-37.

Drew, DAVID (1983) - Man-Environment processes.London, George Allen \& Unwin.

Fauqėres, L. (1991) - "La géo-cindynique, Géo-science du risque". Bull. Assoc. Géogr. Franç, Patis, 3, p. 179-193.

FERreira, A. BrUm (1978) - Planaltos e montanhas do Norte da Beira. Memórias, $\mathrm{n}^{\circ}$ 4. Lisboa, CEG.

GarCiA-Ruz, J.M. et al. (1990) - "Effets géomorphologiques des activités humaines dans les milieux supraforestiers des Pyrentes espagnoles". Revue Géographique des Pyrénées et du Sudouest, Toulouse, 61 (2), p. 255-270.

GodARD, A. (1977) - Pays et paysages du granite. Paris, PUF.

LOURENÇO, LuClano (1988) - "Efeitos do temporal de 23 de Junho de 1988 na intensificação da erosão das vertentes afectadas pelo incêndio florestal de Arganil / Oliveira do Hospital". Comunicações e conclusóes do Seminário Técnico sobre Parques e Conservação da Natureza nos Países do Sul da Europa, Faro, p. 43-77.

MuXART, T. et al (1990) - L'érosion sur les hautes terres du Lingas: 
un processus naturel, une production sociale. Paris, CNRS.

NeBort, R. (1979) - "Les facteurs naturels et les facteurs humains de la morphogenèse. Essai de mise au point". Ann. Géogr.p. 649670.

NEвort, R. (1980) - "Morphogenèse et occupation humaine dans l'Antiquité". Bull. Assoc. Géogr. Fr., p: 21-27.

Nebort, R.(1991) - L'Homme et l'érosion. L'érosion des sols dans le monde, $2 \mathrm{e}$ Édition, Faculté des Lettres et Sciences Humaines de l'Université Blaise-Pascal, Clermont-Ferrand.

Nebort, R. et al (1984) - "L'homme, agent de l'evolution du milieu physique". Actes de 25e CongrèsInternational de Géographie, Paris, thème 2, p. 22-31.

NeBort, R. et al (1990) - "Dynamique rapide et modelé des versants supra-forestiers dans les hautes Tatra polonaises". Rev. Géogr. Apl.p. 259-280.

Pedrosa, A. (1991 a) - "Um caso particular de erosão dos granitos na Serra do Marão". Cadernos de Geografia, Coimbra, I.E.G., 10, p. 537-549.

Pedrosa, A. (1991 b) - "Consequências de situações meteorológicas anormais: breve reflexão". Revista da Faculdade de Letras Geografia, I série, Vol. VII, p. 41-55.

Pedrosa, A. (1992) - "Alguns processos erosivos: o exemplo de um pequenoafloramento graníticoda Serra doMarão". Cuadernos do Laboratorio Xeologico de Laxe, o Castro, 17, p. 107-120.

Pedrosa, A. (1993) - Serra do Marão: Estudo de Geomorfologia. Dissertação de Doutoramento, Faculdade de Letras da Universidade do Porto, Porto.

Pedrosa, A. (1994) - "Contributo para o conhecimento da dinâmica geomorfológica das serras do Norte de Portugal: o exemplo da Serra do Marão". Rurália, Arouca, p. 69-90.

Pedrosa, A.; Marques, B. S. (1992) - "Man's action and slope erosion. The catastrophe in Arosa". Comunicação apresentada ao Symposium Time, Frequency and Dating in Geomorphology (no prelo).

Rebelo, F. (1975) - Serras de Valongo. Estudo de geomorfologia.
Suplementos de Biblos, 9, Coimbra.

ReBelo, F. (1977) - "A acção humana como causa de desabamentos e deslizamentos - análise de um caso concreto". Biblos, 57,p. 629-644.

ReBeLo, F. (1981) - "Introdução ao estudo dos processos erosivos actuais na região litoral do norte e centro de Portugal". Revista da Univ. de Coimbra, 29, p. 195-248.

REBELO,F. (1984) - “Adaptaçốes e inadaptaçôes às cristas quartzíticas do Noroeste português". Livro de Homenagem a Orlando Ribeiro, Vol I, Lisboa, C.E.G., p. 321-331.

REBELO, F. (1986) - "Modelado periglaciar de baixa altitude em Portugal". Cadernos da Geografia, 5, Coimbra, p. 127-137.

Rebelo, F.; Pedrosa, A. de Sousa (1993) - "Contribuição da Geomorfologia para o conhecimento neotectónico da área de Valongo - S. Miguel-o-Anjo". El Cuaternario en España y Portugal, volumen 2, Madrid, Instituto Tecnológico Geominero de España \& Associacion Española para el Estudio del Cuaternario, p. 717-727.

Ribeiro, A. (1984) - "Néotectonique du Portugal". Livro de Homenagem a Orlando Ribeiro, Vol I, Lisboa, C.E.G.

ROMANI, J. R. VIDAL. (1984) - "Geomorfologia granítica. Modelos de deformación post-tectónica de los macizos rocozos". Memórias e Notícias, Coimbra, Publ. Mus. Lab. Mineral. da Univ, de Coimbra, $n^{\circ} 97$, p. 143-158

Strahler, A rThur N.; STRAhler, Alan H.(1973) - Environmental geoscience: interaction between Natural systems and Man, John Wiley \& Sons, Nova Iorque.

TWIDALE, C. R. (1982) - Granite landforms. Elsevier, Amsterdam.

TwIDALE, C. R. (1989) - "La iniciatión subsuperficial de las formas granjticas y sus implicaciones en las teorias generales de evolución del paisaje, Cuad. Lab. Xeol. de Laxe, Coruña, 13 p. $49-68$

Zezere, J. (1988) - As costeiras a norte de Lisboa. Dinâmicas de vertentes e cartografia geomorfológica. Estudo de geomorfologia, Dissertação de Mestrado em Geografia Física e Regional, Lisboa. 